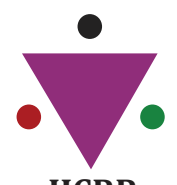

IJCRR

Section: Healthcare

Sci. Journal Impact

Factor: 6.1 (2018)

ICV: 90.90 (2018)

Scopus'

\title{
Study of Aetiology, Complications, Prognostic Factors and Mortality Predictors in Acute Liver Failure in a Tertiary Care Hospital of North India
}

\section{Satish Kumar ${ }^{1}$, Virendra Atam², Satyendra Kumar Sonkar ${ }^{3}$, Ajay Kumar ${ }^{4}$, Harish Gupta ${ }^{4}$, Shyam Chand Chaudhary ${ }^{3}$}

'Senior Resident, Department of Medicine King George's Medical University, Lucknow, India; ${ }^{2}$ Professor and Head, Department of Medicine King George's Medical University, Lucknow, India; 3Professor, Department of Medicine King George's Medical University, Lucknow, India; ${ }^{4}$ Associate Professor, Department of Medicine King George's Medical University, Lucknow, India.

\section{ABSTRACT}

Background: Acute liver failure (ALF) is an entity with rapid deterioration of liver functions which is associated with increased morbidity and mortality.

Methods: Data recorded in terms of aetiology, complications, prognostic factors and mortality predictors in a defined period of January 2018-January 2019. Univariate analysis was done to compare several parameters of survivors and expired patients and then all significant parameters were fed into a sequential logistic regression analysis to determine independent parameters of prognosis.

Results: A total of 100 patients [56 males and 44 females: age (mean \pm SD) $30.13 \pm 13.32$ years] with acute liver failure were enrolled in the study. Among these, 70 (70\%) patients died due to the development of complications. In this study acute liver failure was caused by Hepatitis E virus in 44(44\%) patients, hepatitis A virus in $19(19 \%)$, hepatitis B virus in 10 (10\%), hepatitis $C$ virus in $2(2 \%)$, and hepatitis non $A$ to $E$ in 17(17\%). The number of female patients was 44of which, 35 were in childbearing age, $24(68.57 \%)$ were pregnant and 20(83.33\%) were in the third trimester. Hepatitis E was found positive in $22(91.66 \%)$ pregnant women.

Conclusion: Hepatitis $\mathrm{E}$ was found as the commonest cause of acute liver failure and also in most of the pregnant women, mostly in the third trimester were affected. Initial bad prognostic indicators were non-hepatitis $\mathrm{E}$ aetiology, prothrombin time $>30$ $\mathrm{s}$, coma grade $>2$ and age $>40$ years.

Key Words: Viral hepatitis, Hepatitis E virus, Pregnancy, Non-hepatitis E

\section{INTRODUCTION}

Acute liver failure (ALF) is a rare clinical syndrome with rapid disease progression causing very high morbidity and mortality within a short interval of time. ${ }^{1}$ ALF manifests with severe injury and massive necrosis of hepatocytes causing severe liver dysfunction. It is a life-threatening emergency, but a potentially reversible condition, of varied aetiology, featured by jaundice, hepatic encephalopathy and coagulopathy causing multiple organ dysfunction in a patient without previous history of liver disease. ${ }^{1,2}$ Management is based on the early finding of the aetiology, complications, and general supportive care. But despite the advanced intensive care unit (ICU), mortality in ALF may be up to 40 to $80 \% .^{3}$ These patients have a very poor prognosis and liver transplantation has made a good impact on their survival. ${ }^{4}$ Chances of spontaneous recovery in these patients are defined by some prognostic criteria used by transplant centres in the West. ${ }^{5}$ Liver transplantation is newer in developing countries and clinicians there, should know prognostic factors of ALF before managing a patient of acute liver failure. Criteria defining prognosis in western countries may or may not be similar for developing countries like India, because different geographical regions have different aetiology for ALF, hence different prognostic factors. ${ }^{6}$ The aetiology of ALF also varies according to the age of the patient. ${ }^{7}$ In the West, aetiology is confined mainly to hepatitis non A to E (Hn A-E), acetaminophen overdose, and idiosyncratic drug reactions ${ }^{8}$ while

\section{Corresponding Author:}

Dr. Satish Kumar, Senior Resident, Department of Medicine King George's Medical University, Lucknow, India; Email: dr.satishkgmu@gmail.com

ISSN: 2231-2196 (Print)

Received: 01.05 .2020
ISSN: 0975-5241 (Online)

Revised: 13.06 .2020
Accepted: 08.07 .2020
Published: 22.07 .2020 
on another side in Indian subcontinent main causes for ALF is hepatitis E virus (HEV). ${ }^{9}$ Pregnant women are prone to get infected with HEV, and progression to ALF will affect the prognosis and thought of liver transplantation. ${ }^{10}$ Hepatitis $\mathrm{C}$ virus is not considered to cause ALF in the absence of a coexisting aetiology. Although, case reports are there. This study was done to study the aetiology, complications, prognostic factors and mortality indicators in 100 patients with ALF in a tertiary care hospital of North India.

\section{PATIENTS}

This study was a retrospective cross-sectional study that enrolled all consecutive patients of ALF admitted to the ICU and high dependency unit (HDU) of the department of medicine at King George's Medical University, Lucknow during January 2018-January 2019. Consent was taken from all admitted subjects. All patients were given standard supportive care and strict monitoring of clinical, biochemical and hemodynamic status. Women in the age group of $15-45$ years who were married were also tested for pregnancy status by human chorionic gonadotropin (HCG) hormone in urine and ultrasonography pelvic region for estimation of gestational age. Pregnant women were managed conservatively and no efforts were made to deliver the pregnancy unless otherwise absolutely indicated by obstetricians. No, any patient was treated by liver transplantation. The most widely accepted definition from the American Association for the Study of Liver Diseases (AASLD) is "evidence of coagulation abnormality, usually an international normalized ratio above 1.5 , and any degree of mental alteration (encephalopathy) in a patient without pre-existing liver disease and with an illness of fewer than 26 weeks' duration. ${ }^{11,12}$ The prognosis was determined by variables at the time of hospitalization. Complications such as cerebral oedema, renal failure, and gastrointestinal bleeding were noticed within $48 \mathrm{~h}$ of admission and were kept for analysis.

\section{METHODS}

Data of admitted patients with acute liver failure were collected from Jan 2018 to Jan 2019. A total of 100 patients of acute liver failure were enrolled in the study. Data was collected in terms of clinical, biochemical, aetiology, complications, prognostic factors and mortality predictors. Routine investigations were complete blood count, liver function test (LFT), renal function, serum sodium, serum potassium, prothrombin time, international normalised ratio(INR), and ultrasonography abdomen(USG). Sera of all acute phase was investigated by enzyme-linked immunosorbent assay (ELISA) for markers of hepatitis A virus (HAV) (IgM anti-HAV), hepatitis B virus (HBV) (HBsAg and IgM anti-HBc), hepatitis C virus (HCV) (anti-HCV second generation) and hepatitis D virus (HDV) (IgG and IgM anti-HDV) with commercially available kits along with ELISA for IgM and IgG antibodies to HEV by a kit using two recombinant HEV antigens.

PCR reaction was done when necessary. The patient's co morbid conditions were noted. Those who had a history or had clinical/imaging/biochemical features of chronic liver disease and a history of significant alcohol ingestion $(>20$ gm daily) were excluded from the study. Any previous abdominal surgery, malignancies, gallstones, and cardiac diseases were also excluded. Liver biopsy could not be done as none of the patients' attendants consented for

the procedure. On the behalf of positive findings of above viral markers, hepatitis was divided into hepatitis A (presence of IgM anti- HAV), acute hepatitis B (presence of HBsAg and IgM anti- $\mathrm{HBc}$ ), acute hepatitis on a pre-existing hepatitis B carrier state (presence of HBsAgwith no IgM anti$\mathrm{HBc}$ ) and hepatitis D (presence of IgG or IgM anti-HDV and HBsAg). Hepatitis E was confirmed by positivity for IgM anti-HEV in the serum of cases or seroconversion to IgG anti-HEV alone in convalescent sera. Positivity of anti-HCV and HCV RNA diagnosed hepatitis $\mathrm{C}$ infection. Aetiology of hepatitis non A to $\mathrm{E}$ (HnA-E) was diagnosed in those patients which have clinical, biochemical and radiological features of acute hepatitis, negative aetiologies of viral hepatitis A, B, C, D and E, no history of intake of drugs, hepatotoxins, systemic infections and biliary obstruction/infection.

\section{STATISTICAL METHODS}

Statistical analysis was performed using SPSS Statistics software. Baseline characteristics were assessed with standard descriptive statistics. Quantitative variables were compared using the independent $t$-test and Mann-Whitney test (for nonparametric data) between two groups. Qualitative variables were compared using the Chi-square test/Fisher's exact test. Pearson correlation coefficient was used to find correlation between various variables. Multivariate regression analysis was performed to examine the relationship between various parameters after adjusting for confounders.

\section{RESULTS}

Among all 100 admitted patients of acute liver failure, 70 expired. Major etiology behind ALF was hepatitis viruses (Table 1).

Mortality rates were compared among all viral hepatitis patients, it was $80 \%$ in $\mathrm{HBV}, 100 \%$ in HCV, $88.23 \%$ in hepatitis non A to E (HnA-E) and all did not differ significantly. $(\mathrm{p}=0.45$ ) while the mortality rate in ALF caused by HEV $(45.45 \%)$ was found lesser than others which were significant $(\mathrm{P}<0.001$ in almost all). 
Pre-existing HBV carrier state was found in ten (10\%) patients and these had super infection by other hepatitis viruses. Eight $(80 \%)$ of these died. Cryptic hepatitis B infection was not recorded in any patient. Clinical and hematological parameters of ALF patients with the aetiology of HBV, HCV, and HnA-E were almost similar. All non-E patients of ALF were subgroups and analyzed. Comparison of clinical and haematological parameters of HEV and non- hepatitis E patients are shown in Table 2.

ALF patients in the third and fourth decades of life ( $72 \%$ of patients) were highly affected.ALF patients with the aetiology of hepatitis E were younger than the non-hepatitis E related ALF patients. Hepatitis A infection was found in the lower age group of $<15$ years of age. Male to female ratio among ALF patients was 1.27:1 with a higher prevalence of females in HEV (59.09\%) than those in the non-E group (32.14\%).

Among all the 44 female patients, 35 were in childbearing age (15-45 years), 24 (68.57\%) were pregnant and 20 $(83.33 \%)$ of these were in the third trimester of gestation. HEV infection was found in $22(91.66 \%)$ pregnant women.

The occurrence of HEV in pregnancy was higher (91.66\%) against $20 \%$ in non-pregnant women which were significant $(\mathrm{P}<0.001)$. The period from onset of jaundice to initiation of hepatic encephalopathy, pre-encephalopathy period (PEP) was significantly lesser in HEV patients than those in nonhepatitis E patients. All HEV patients with ALF were having PEP less than 28 days while the non-hepatitis E group was having PEP more than 28 days and it was significant $(\mathrm{P}<$ 0.001).

It was observed that patients with non-hepatitis E aetiology were having high grades of hepatic encephalopathy and also have more complications such as sepsis, renal failure and gastrointestinal bleeding in comparison to HEV group.

It was found that expired patients with ALF were older, longer PEP, higher grade of encephalopathy, presence of cerebral oedema, sepsis and renal failure at admission, prolonged prothrombin time and a higher proportion of patients with non-E aetiology in comparison to survived ALF patients (Table 3).

Survived and expired group had similarity in parameters such as the occurrence of gastrointestinal bleeding, percentage of pregnant women, haemoglobin, total leukocyte count, platelet count, liver function test, serum sodium, serum potassium, serum amylase and arterial blood gas(ABG)parameters like $\mathrm{PaO} 2, \mathrm{pcO} 2, \mathrm{sP} 2$, arterial $\mathrm{pH}$ and serum lactate (parameters are not shown in the article).

Variables that were differed significantly on univariate analysis in survivors and expired ALF patients were age $>40$ years, cerebral oedema, coma grade $>2$, prothrombin time $>30 \mathrm{~s}$, non-hepatitis E aetiology of ALF, sepsis and renal failure at presentation. Among all these seven parameters multivariate analysis significance was found with coma grade $>2$, age $>40$ years, non-hepatitis E aetiology and prothrombin time $>30 \mathrm{~s}$. The outcome was most significantly associated with etiology.HEV as aetiology of ALF was associated with a good outcome while non-hepatitis $\mathrm{E}$ agents were bad prognostic factors. Prothrombin time $>30 \mathrm{~s}$ was the next significant predictor of outcome which was found in 37 patients and caused $34(91.89 \%)$ of the expiries. In decreasing order age $>40$ years was the next to affect the outcome. Among 21 patients, $19(90.47 \%)$ deaths occurred. Coma grade $>2$ was observed in 76 patients and resulted in $60(78.94 \%)$ expiries. It was concluded that, with more number of bad prognostic factors, the mortality was higher (Table 4).

\section{DISCUSSION}

This study was done on the patients admitted in the intensive care unit and high dependency wards of the medicine department of a tertiary care hospital were all potential patients come to admit. Cause for acute liver failure in our all admitted patients was either known or putative hepatitis viruses. Though ALF could be a result of several aetiological factors, the most common cause in the United Kingdom is concerned with acetaminophen (non-steroidal anti-inflammatory drugs) poisoning concerning suicidal tendencies ${ }^{13,14}$ and commonest cause in India was viral hepatitis and it was HEV. ${ }^{15}$ No one of our patients had ALF with the aetiology of acetaminophen poisoning which may be due to the use of some other agent for the suicidal attempt. Those patients who were having negative viral markers for hepatitis were named Hn A-E in the current study. Among Hn A-E some patients were linked with contact to some unknown 'herbs' (drug-induced liver injury-DILI) or toxins and they could not be identified due to lack of reliable biomarkers. ${ }^{16}$ Remaining liver diseases constituting a very lesser number of cases are liver diseases unique in pregnancy, metabolic and vascular liver diseases, and so many of miscellaneous liver diseases. ${ }^{12}$ In the current study hepatitis, A and $\mathrm{E}$ were the commonest aetiology. In developing countries such as India, HAV is highly pathogenic and spreads via transmission from one to another person. On the other side HEV is a labile agent that spreads via contaminated water and does not have person-to-person transmission. ${ }^{17}$ In endemic areas of HEV, anti-HEV seroprevalence ranges from 5-20\%, which becomes higher with increasing age and as a result, most of the adults are prone to HEV exposure. ${ }^{18}$ Due to these conditions, HEV infection is mainly a disease of the adult group. ${ }^{17,19}$ Many studies from India have concluded hepatitis $\mathrm{C}$ in the non-A, non-B group of patients ${ }^{20,21}$ in causing ALF and also in this study $\mathrm{HCV}$ infection was determined in $2 \%$ of patients. But this could not be determined that HCV was causing ALF or it was representing pre-existing carrier state and another factor 
caused ALF. HnA-E constitutes $30-50 \%$ of cases of ALF in the West and this putative agent formed $2 \%$ of patients in the present study. Maximum 44 patients of ALF were associated with HEV constituting of largest aetiology of ALF. Kashmir state of India is endemic for HEV and it constitutes the commonest aetiology there and in other endemic areas of the world. ${ }^{22}$ In this study, it was observed that HEV is highly prevalent in pregnant women and there were 22 (91.67\%) pregnant women having HEV positivity among a total of 24 pregnant women. It reflects endemicity of HEV in this state. This finding is the most distinctive epidemiological feature of ALF in the current study. In pregnancy viral hepatitis is a matter of dispute because study data in the West says acute viral hepatitis $(\mathrm{AVH})$ is not prevalent in pregnancy and if occurred it will have a similar disease course as in nonpregnant. ${ }^{20}$ While in developing nations like India, viral hepatitis is highly prevalent in pregnant with more severity. ${ }^{13,23,24}$ This is due to the different aetiology of AVH in the West and developing nations. In this study above predilection is consistent. ALF due to non $\mathrm{E}$ hepatitis viruses did not have a higher attack rate and fatality in comparison to HEV in pregnancy. In the current study, it was found that HEV has increased prevalence and fatality in pregnancy but pregnancy itself or its gestation didn't affect mortality in ALF. ${ }^{10}$ Although ALF is predominant in pregnancy, it means not that there will be higher mortality in comparison to ALF in non-pregnant women and men. Mortality of patients of ALF in pregnancy will depend on all prognostic factors and not on the pregnancy or gestational period.

There was a significant influence of PEP on mortality in our study and it showed that patients with PEP less than 8 days have non significantly lower $(63.63 \%)$ mortality in comparison to significantly higher mortality in those with PEP more than 8 days (77.78\%). While a study was done in New Delhi, India reported that there is no influence of PEP on the prognosis and severity of ALF. ${ }^{9}$ In this study, it was also found that cerebral oedema at presentation was in $56 \%$ of patients, which caused fatal results in $89.28 \%$ of patients. Late admission to hospital care was responsible for a greater number of patients with cerebral oedema. Finding some more complications such as renal failure, sepsis, and gastrointestinal bleeding was also found in some studies done in western and in India. ${ }^{1}$

Prognosis in our study was significantly associated with the aetiology of ALF as HEV patients with ALF have a mortality of $45.45 \%$ in comparison to higher mortality (88.23\%) caused by HBV, HCV, and Hn A-E. While another study from India could not find aetiology as a prognostic indicator in ALF ${ }^{6}$ Western studies say Hn A-E and drugs are bad indicators of prognosis. ${ }^{5} \mathrm{ALF}$ due to HEV had a favourable outcome while those due to Hn A-E factors had bad results. The assessment of these parameters separately results in a significant impact on survival.

\section{CONCLUSION}

In this study of 100 patients, we found that known or putative hepatitis viruses caused ALF in a maximum number of patients. Among all aetiologies of ALF, HEV caused maximum cases. Pregnancy was observed in about one- fourth of ALF patients and, all but two patients were HEV positive. Pregnancy itself or a gestational period not affects results. Early bad prognostic indicators were prothrombin time greater than 30 seconds, age more than 40 years and coma grade more than 2.

Acknowledgment-Authorsare grateful to all patients, clinicians and other medical staff involved in this study. Authors acknowledge the immense help received from the scholars whose articles are cited and included in references of this manuscript. The authors are also grateful to authors / editors / publishers of all those articles, journals and books from where the literature for this article has been reviewed and discussed.

\section{Conflict of interest-None}

Financial support- None

\section{REFERENCES}

1. Hoofnagle JH, Carithers RL Jr, Shapiro C, Ascher N. Ful- minant hepatic failure: summary of a workshop. Hepatology 1995; 21: $240-252$.

2. Bucuvalas J, Yazigi N, Squires R. Acute liver failure in children. Clin Liver Dis. 2006; 10: 149-68.

3. Gill RQ, Sterling RK. Acute liver failure. J Clin Gastroenterol. 2001 Sep;33(3):191-198.

4. Bismuth H, Samuel D, Castaing D, Wililams R, Pereira SP. Liver transplantation in Europe for patients with acute liver failure. Semin Liver Dis 1996; 16: 415-425.

5. Bernuau JB, Goudeau A, Poynard T et al. Multivariate analysis of prognostic factors in fulminant hepatitis B. Hepatology 1986; 6: 646-651.

6. Lee WM, Sorrell MF. Developing a world view toward acute liver failure.Hepatology 1996; 24: 270-271.

7. Ostapowicz J, Lee WM. Acute hepatic failure: a western perspective. J Gastroenterol Hepatol. 2000;15;480-8.

8. Bernuau J, Rueff B, Benhamou JP. Fulminant and subful- minant liver failure; definition and causes.Semin Liver Dis 1986; 6: 97-106.

9. Acharya SK, Dasarathy S, Kumer TL et al. Fulminant hepatitis in a tropical population: clinical course, cause, and early predictors of outcome. Hepatology 1996; 23: 1448- 1455.

10. Khuroo MS, Teli MR, Skidmore S, Sofi MA, Khuroo MI. Incidence and severity of viral hepatitis in pregnancy. Am J Med 1981; 70: 252-255.

11. Lee WM, Larson AM, Stravitz RT. AASLD position paper: The management of acute liver failure: Update 2011. Association for the Study of Liver Diseases website. http://www.aasld.org/practiceguidelines/Documents/AcuteLiverFailureUpdate2011.pdf. Published 2011. Accessed August 16, 2017.

12. Khuroo MS, Datta DV. Budd-Chiari syndrome following pregnancy.Report of 16 cases with roentgenologichemo- dynamic and histologic studies of the hepatic outflow tract.Am J Med 1980; 68: 113-121. 
13. Riordan SM, Williams R. Treatment of hepatic encephal- opathy. N Eng J Med 1997; 337: 473-478.

14. O'Grady JG, Schalm SW, Williams R. Acute liver failure: redefining the syndromes. Lancet 1993; 352: 273-275.

15. Acharya SK, Batra Y, Hazari S, Choudhury V, Panda SK, Dattagupta S. Etiopathogenesis of acute hepatic failure: Eastern versus Western countries. J Gastroenteral Hepatol. 2002 Dec 17;(suppl 3):S268-273.

16. Datta DV, Khuroo MS, Mattocks AR, Aikat BK, Chhuttain PN. Herbal medicines and veno-occlusive disease in India.Postgraduate Medical J 1978; 54: 511-515.

17. Khuroo MS. Study of an epidemic of non-A, non-B hepatitis: possibility of another human hepatitis virus distinct from posttransfusion non-A, non-B type. Am J Med 1980; 68: 818-823.

18. Khuroo MS, Khuroo N. Hepatitis E: global epidemiology with special reference to impact of the disease in India and the South East of Asia. In: Rizzetto M, Purcell RH, Gerin JL, Verme G. eds. Viral hepatitis and liver disease, Edizioni Minerva Medica, Turin, 1997: 601-608.
19. Khuroo MS, Rustgi VK, Dawson GJ et al. Spectrum of hepatitisE virus in India. J Med Virol 1994; 43: 281-286.

20. [20].Farci P, Alter H, ShimodaA et al. Hepatitis C virus-associated fulminant hepatic failure. N Engl J Med 1997; 335: 631-634.

21. [21]. Takahashi Y, Shimizu M. Aetiology and prognosis of fulminant viral hepatitis in Japan: a multicentric study. J Gastroenterol Hepatol 1991; 6: 159-164.

22. [22].Ramaliingaswami V, Purcell RH. Waterborne Non-A, nonB hepatitis.Lancet 1988; 1: 571-573.

23. [23].Arankalle VA, Jha J, Favorov MO, Chaudari A, Fields HA, Bannerjee K. Contribution of HEV and HCV in causing fulminant non-A, non-B hepatitis in western India. Journal of Viral Hepatitis 1995; 2: 189-193.

24. [24].Arankalle VA, Chadha MS, Dama BM, Tsarev SA, Purcell $\mathrm{RH}$, Bannerjee K. Role of immune serum globulins in pregnant women during an epidemic of hepatitis E. J Viral Hepatitis 1998; 5: 199-204.

Table 1: Showing different aetiologies of acute liver failure

\begin{tabular}{|c|c|c|c|c|c|}
\hline \multirow[b]{2}{*}{ S. $\mathbf{N}$. } & \multicolumn{3}{|c|}{ Pre-existing carrier state of Hepatitis B } & \multirow[b]{2}{*}{ Total (100) } & \multirow[b]{2}{*}{ Expiries (70) } \\
\hline & Aetiology & Positive (10) & Negative (9o) & & \\
\hline 1. & Hepatitis E & 4 & 40 & $44(44 \%)$ & 20 \\
\hline 2. & Hepatitis D & 2 & 5 & $7(7 \%)$ & 7 \\
\hline 3. & Hepatitis C & 2 & - & $2(2 \%)$ & 2 \\
\hline 4. & Acute Hepatitis B & - & 10 & $10(10 \%)$ & 8 \\
\hline 5 & Hepatitis A & - & 19 & $19(19 \%)$ & 17 \\
\hline 6. & Drugs & - & 1 & $1(1 \%)$ & 1 \\
\hline 7. & Hepatitis non A-E (HnA-E) & 2 & 15 & $17(17 \%)$ & 15 \\
\hline
\end{tabular}

Table 2: Showing clinical characteristics of acute liver failure patients

\begin{tabular}{|c|c|c|c|c|c|}
\hline SN & Characteristics & Hepatitis E & Non-hepatitis E & Total & Pvalue \\
\hline 1. & No. of patients & 44 & 56 & 100 & \multirow{4}{*}{0.036} \\
\hline \multirow[t]{3}{*}{2.} & Age in years & & & & \\
\hline & Mean+/-SD & $27.1+/-7.8$ & $32.3+/-15.8$ & $30.13+/-13 \cdot 32$ & \\
\hline & Range of age & $15-55$ & $16-70$ & $15-70$ & \\
\hline \multirow[t]{3}{*}{3.} & Sex $(M: F)$ & $18: 26$ & $38: 18$ & $56: 44$ & $<0.007$ \\
\hline & Pregnancies & 22 & 2 & 24 & \multirow[t]{2}{*}{$<0.001$} \\
\hline & Non pregnants( $15-45$ years) & 4 & 16 & 20 & \\
\hline \multirow[t]{3}{*}{4.} & PEP (Days) & & & & \multirow{3}{*}{$<0.001$} \\
\hline & Mean+/-SD & $5 \cdot 9+/-4 \cdot 7$ & $27 \cdot 7+/-26.7$ & $18.8+/-23.4$ & \\
\hline & Range & $1-26$ & $1-145$ & $1-52$ & \\
\hline \multirow[t]{6}{*}{5.} & Coma grading & & & & \\
\hline & Mean+/-SD & $3.1+/-0.9$ & $3 \cdot 5^{+/-0.7}$ & $3 \cdot 33+/-0.81$ & 0.021 \\
\hline & I & 9 & 4 & 13 & \multirow{4}{*}{0.007} \\
\hline & II & 12 & 10 & 22 & \\
\hline & III & 15 & 14 & 29 & \\
\hline & IV & 8 & 28 & 36 & \\
\hline
\end{tabular}


Table 2: (Continued)

\begin{tabular}{|c|c|c|c|c|c|}
\hline SN & Characteristics & Hepatitis E & Non-hepatitis E & Total & P value \\
\hline \multirow[t]{5}{*}{6.} & Number of Patients & & & & \multirow{5}{*}{$<0.001$} \\
\hline & $<1$ week & 30 & 10 & 40 & \\
\hline & 1 week-1 month & 10 & 22 & 32 & \\
\hline & 1 month -2 months & 2 & 16 & 18 & \\
\hline & $>2$ months & 2 & 8 & 10 & \\
\hline 7. & Hepatitis B carrier & 4 & 6 & 10 & 0.788 \\
\hline \multirow[t]{3}{*}{8.} & Serum bilirubin umol/l & & & & \\
\hline & Mean+/-SD & $306+/-171$ & $399+/-221$ & $360.25^{+/-206.8}$ & \multirow{2}{*}{0.022} \\
\hline & Range & $104-745$ & $60-1032$ & 6o-1032 & \\
\hline \multirow[t]{3}{*}{9.} & Serum ALT (U/L) & & & & \multirow{3}{*}{0.119} \\
\hline & Mean+/-SD & $540+/-421$ & $777+/-1012$ & $678.25+/-827.6$ & \\
\hline & Range & $188-2341$ & $225-5723$ & $188-5723$ & \\
\hline \multirow[t]{3}{*}{10.} & Prothrombin time (s) & & & & \multirow{3}{*}{0.169} \\
\hline & Mean+/-SD & $28.2+/-11.9$ & $31.5+/-10.9$ & $30.12+/-11.44$ & \\
\hline & Range & 18-50 & $19-62$ & $18-62$ & \\
\hline \multirow[t]{5}{*}{11.} & $\begin{array}{l}\text { Complications (no. of } \\
\text { paients) }\end{array}$ & & & & \\
\hline & Septicemia & 21 & 45 & 66 & $<0.05$ \\
\hline & Renal failure & 10 & 44 & 54 & $<0.001$ \\
\hline & GIB & 13 & 32 & 45 & 0.006 \\
\hline & Cerebral edema & 42 & 48 & 90 & 0.107 \\
\hline 12. & Expiries & $20(45.5 \%)$ & $50(89.3 \%)$ & $70(70 \%)$ & $<0.001$ \\
\hline
\end{tabular}

PEP-pre-encephalopathy period, ALT-alanine aminotransferase, GIB-Gastro intestinal bleed

Table 3: Comparison of variables as prognostic factors between survivors and expired patients of acute liver failure

\begin{tabular}{|c|c|c|c|c|c|}
\hline SN & Variables & $\begin{array}{c}\text { Survived } \\
\mathrm{N}=30\end{array}$ & $\begin{array}{l}\text { Expired } \\
\quad \mathbf{N}=70\end{array}$ & $\begin{array}{c}\text { Chi square test } \\
\text { Pvalue }\end{array}$ & $\begin{array}{c}\text { Students - t test } \\
\text { P value }\end{array}$ \\
\hline \multirow[t]{3}{*}{1.} & $\begin{array}{l}\text { Age (Years) } \\
\text { Mean+/-SD }\end{array}$ & $25 \cdot 5^{+/-10.8}$ & $32.1+/-14.2$ & 0.011 & \\
\hline & $<40$ Years & 28 & 51 & 0.021 & 0.010 \\
\hline & $>40$ years & 2 & 19 & & \\
\hline \multirow[t]{3}{*}{2.} & Sex (no. of patients) & & & & \\
\hline & Males & 14 & 42 & 0.218 & \\
\hline & Females & 16 & 28 & & \\
\hline \multirow[t]{4}{*}{3} & PEP (DAYS) Mean+/-SD & $11.5^{+/-17.8}$ & $21.5^{+/-24.7}$ & 0.01 & \\
\hline & No. of patients & & & & \\
\hline & $<1$ week & 20 & 35 & $<0.125$ & 0.61 \\
\hline & >1 week & 10 & 35 & & \\
\hline \multirow[t]{3}{*}{4.} & $\begin{array}{l}\text { Grade of coma } \\
\text { (no. of patients) }\end{array}$ & & & & \\
\hline & Grade1 and 2 & 14 & 10 & $<0.001$ & 0.006 \\
\hline & Grade 3 and 4 & 16 & 60 & & \\
\hline
\end{tabular}


Table 3: (Continued)

\begin{tabular}{|c|c|c|c|c|c|}
\hline SN & Variables & $\begin{array}{c}\text { Survived } \\
\qquad N=30\end{array}$ & $\begin{array}{c}\text { Expired } \\
\mathbf{N}=\mathbf{7 0}\end{array}$ & $\begin{array}{c}\text { Chi square test } \\
\text { P value }\end{array}$ & $\begin{array}{c}\text { Students -t test } \\
\text { Pvalue }\end{array}$ \\
\hline \multirow[t]{4}{*}{5.} & $\begin{array}{l}\text { Complications } \\
\text { (no.ofpatients) }\end{array}$ & & & & \\
\hline & Cerebral edema & 6 & 50 & $<0.001$ & 0.55 \\
\hline & Septicemia & 8 & 45 & & 0.54 \\
\hline & Renal failure & 3 & 30 & & 0.35 \\
\hline \multirow[t]{4}{*}{6.} & $\begin{array}{l}\text { Prothrombin time } \\
(\text { mean+/-SD) }\end{array}$ & $23.1+/-6.7$ & $30.5^{+/-11.8}$ & $<0.001$ & \\
\hline & Number of patients & & & & \\
\hline & $>30$ seconds & 27 & 36 & $<0.001$ & 0.05 \\
\hline & $<30$ seconds & 3 & 34 & & \\
\hline \multirow[t]{3}{*}{7.} & $\begin{array}{l}\text { Aetiology } \\
\text { (no. of patients) }\end{array}$ & & & & \\
\hline & Hepatitis E & 20 & 24 & $<0.003$ & 0.003 \\
\hline & Non-hepatitis E & 10 & 46 & & \\
\hline
\end{tabular}

Table 4: Determinants of prognostic factors

\begin{tabular}{lcccc} 
Determinants & Number & Expiries & Sensitivity & Specificity \\
Non E causes & 56 & 48 & 89.2 & 48.1 \\
Coma gr $>2$ & 76 & 60 & 86.2 & 69.9 \\
PT $>30$ S & 37 & 34 & 94.1 & 40.1 \\
Age $>40$ & 21 & 19 & 90.1 & 33.1 \\
\hline
\end{tabular}

